\title{
Cell therapy for cerebral hemorrhage: Five year follow-up report
}

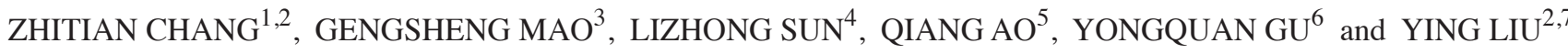 \\ ${ }^{1}$ Department of Neurosurgery, Siping Hospital of China Medical University; ${ }^{2}$ Tuhua Bioengineering Company Ltd., \\ Siping, Jilin 136000; ${ }^{3}$ Department of Neurovascular Surgery, General Hospital of Armed Police Forces, Beijing 100000; \\ ${ }^{4}$ Department of Neurobiology of North China University, Jilin 132013; ${ }^{5}$ Department of Tissue Engineering, \\ China Medical University, Shenyang, Liaoning 110122; ${ }^{6}$ Department of Vascular Surgery, Xuanwu Hospital, \\ Capital Medical University, Beijing 100053; ${ }^{7}$ The Key Tissue Engineering Laboratory of Jilin Province, \\ Jilin 136000, P.R. China
}

Received February 25, 2016; Accepted September 6, 2016

DOI: 10.3892/etm.2016.3811

\begin{abstract}
The aim of the study was to examine treatment of cerebral hemorrhages with bone-marrow or human umbilical cord-derived mesenchymal stem cells (BMSCs or Hu-MSCs) and conventional surgical approaches, and determine and compare the effectiveness, feasibility, safety and reproducibility of each method. A retrospective analysis was performed on a cohort of cell-treated cerebral hemorrhage patients from October 1, 2007 to October 1, 2009. A total of 24 patients, all of whom received conventional surgical treatment, were classified as follows: i) The control group consisted of 8 patients who received only hematoma removal surgery, ii) the autologous group consisted of 7 patients who received additional autologous bone marrow mononuclear cell transplantation, and iii) the allograft group consisted of 9 patients who received additional umbilical cord mononuclear cell transplantation. After conventional hematoma removal surgery and X-ray supervision within $24 \mathrm{~h}$ and at 7 days, neurological disability and function tests were completed 3 , 6, 12, 36 and 60 months later. The T-cell marker plasma levels were analyzed after 60 months. The results showed that, at approximately 3.5 months after graft the hematomas in all the
\end{abstract}

Correspondence to: Professor Ying Liu, The Key Tissue Engineering Laboratory of Jilin Province, 89 Nanyingbin Road, Siping, Jilin 136000, P.R. China

E-mail: 1y3641829@163.com

Dr Yongquan Gu, Department of Vascular Surgery, Xuanwu Hospital, Capital Medical University, 45 Changchun Street, Beijing 100053, P.R. China

E-mail: yongquan_gu@126.com

Key words: human umbilical cord-derived mesenchymal stem cells, cerebral hemorrhage, CD4, CD8, CD56, human leukocyte antigen-DR groups were completely reabsorbed as observed on computed tomography scans. However, the functional outcomes in the cell-transplanted groups were better than in the control group after 5 years. While the National Institutes of Health Stroke Scale, modified Rankin score and modified Barthel index scores were simliar in the cell-transplanted groups, patients in the allograft group had better outcomes than those in the autologous graft group starting at 3 months and until the end of the follow-up period. The serum levels of T-cell markers CD4, CD56 and human leukocyte antigen-DR in the allograft group showed no signs of immunogenic graft complications and there were no significant differences in T-cell subtypes among the patient groups. The results of the present study suggest that, treatment of cerebral hemorrhage patients can be safely and effectively accomplished using Hu-MSC grafting and larger clinical trials should be considered in the future.

\section{Introduction}

Cerebral hemorrhage remains a worldwide health burden, causing high morbidity, mortality, and costs to health care systems, and is the primary cause of serious long-term disabilities in the developed and developing countries (1). Recent advances in stem cell research have led to the development of cell-based therapies for tissue damage caused by injury or disease (2). This growing field of medicine brings the promise of stem cell therapies that may restore the original tissues. In this pursuit, advancements in neurogenesis through the use of mesenchymal stem cells (MSCs) may provide the fundamental components that are missing from classical single molecule-based pharmaceutical interventions to enhance functional recovery after a cerebral hemorrhagic episode.

MSCs are a heterogeneous population of stem cells that are able to differentiate into various cell types, including osteoblasts, chondrocytes, adipocytes and muscle cells (3). The use of human MSCs has shown enormous therapeutic potential in neurological regenerative medicine (4-7). MSCs can be isolated from various tissues, including bone marrow, adipose tissue, synovium, periosteum, skeletal muscles, and umbilical cord 
tissues (8). In previous studies, we demonstrated the immunologic compatibility and osteogenic properties of human umbilical cord-derived mesenchymal stem cells (Hu-MSCs)in tibia non-union in rats $(9,10)$ and patients $(11)$. The primary aim of the present study was to examine in cerebral hemorrhage both with bone marrow mononuclear cells/Hu-MSCs and with conventional surgical approaches, which enhanced regenerative support from transplanted cells to effectively treat acute and chronic disorders of the nervous system. The secondary objective was to determine the safety of cell therapy in patients with cerebral hemorrhage.

\section{Materials and methods}

Study population. A retrospective analysis was performed on a cohort of 24 patients treated for cerebral hemorrhage.The patients were admitted to the Department of Neurosurgery, Siping Hospital of China Medical University (Siping, China) from October 1, 2007 to October 1, 2009.

The present study was approved by the ethics committee of Siping Hospital of China Medical University. All the patients in the cohort were $\geq 18$ years of age. Cerebral hemorrhage patients were treated within the first $6 \mathrm{~h}$ of the onset of the hemorrhagic episode. Patients with life-threatening conditions, limited follow-up, missing stratification information, or without standard indications for rehabilitation were excluded from the study. The criteria for exclusion were chosen to ensure that all the patients were treated according to the best medical practices. Written informed consent was obtained from the patients prior to any and all procedures.

For data analysis, 24 patients were classified into one of three groups, with all groups receiving conventional surgical treatment: group 1, the control group, had 8 patients who received hematoma removal surgery alone; group 2 had 7 patients who received additional autologous bone marrow mononuclear cell transplant; and group 3 had 9 patients who received an additional umbilical cord MSCs allograft instead. The general description of the patients is shown in Table I. Blood was taken from the internal jugular veins.

Definition of cerebral hemorrhage. The diagnosis of cerebral hemorrhage was confirmed on radiographs at the discretion of the admitting doctor (12).

Bone marrow mononuclear cell isolation. Bone marrow mononuclear cells were isolated from $40 \mathrm{ml}$ of bone marrow harvested from the posterior iliac crest of each patient undergoing an autologous transplant. The procedure for harvesting human MSCs followed the method described in our previous study (13). Briefly, the bone marrow samples were washed with Dulbecco's modified Eagle's medium-low glucose (DMEM-LG; Invitrogen Life Technologies, Carlsbad, CA, USA) supplemented with $10 \%$ of an aliquot of the patient's own blood plasma. To isolate the mononuclear cells, the samples were subjected to a preformed Percoll ${ }^{\mathrm{TM}}$ (Sigma, St. Louis, MO, USA) density gradient $(1.073 \mathrm{~g} / \mathrm{ml})$ centrifugation step. The total number of MSCs was $\sim 1.8 \times 10^{8}$ cells for each patient.

Umbilical cord harvesting. Five human umbilical cord (UC), samples were collected after informed written consent was obtained from the mothers. The study protocol was approved by the Institutional Ethics Committee of Siping Hospital of China Medical University and all the experimental animal procedures were in accordance with the national/international guidelines for ethical conduct in the care and use of animals. Regarding each sample, UC sections of 8-10 cm were internally washed with phosphate-buffered saline (PBS) containing $300 \mathrm{U} / \mathrm{ml}$ penicillin and $300 \mathrm{~g} / \mathrm{ml}$ streptomycin (Gibco, Grand Island, NY, USA) and immediately immersed in DMEM-LG (Gibco) supplemented with 10\% fetal bovine serum, $300 \mathrm{U} / \mathrm{ml}$ penicillin, and $0.3 \mathrm{mg} / \mathrm{ml}$ streptomycin. The samples were processed within 12-15 h after collection.

Isolation and culture of adherent cells from the UC. The UCs were filled with $0.1 \%$ collagenase (Sigma-Aldrich, St. Louis, USA) in PBS and incubated at $37^{\circ} \mathrm{C}$ for $20 \mathrm{~min}$ as previously described $(9,10)$. Each UC was washed with proliferation medium and the detached cells were harvested after gentle massage of the UC. The cells were centrifuged at $300 \mathrm{x} \mathrm{g}$ for $10 \mathrm{~min}$, resuspended in proliferation medium, and seeded in $75-\mathrm{cm}^{2}$ flasks at a density of $5 \times 10^{7}$ cells $/ \mathrm{ml}$. After incubation for $24 \mathrm{~h}$, non-adherent cells were removed and the culture medium was replaced every 3 days. Adherent cells were cultured until they reached $80-90 \%$ confluence.

Laboratory measurements. Patient's serum levels of T-cell subtypes were analysed using flow cytometry 5 years after the transplantation.

Flow cytometry. To analyze the cell surface expression of the typical protein markers, adherent cells were incubated with the following anti-human conjugated primary antibodies (BD Biosciences, Franklin Lakes, NJ, USA): CD4-phycoerythrin (PE) (monoclonal, dilution: $0.2 \mu 1 / 1 \times 10^{6}$ cells, catalog no.: 565999); CD8-fluorescein isothiocyanate (monoclonal, dilution: $0.2 \mu \mathrm{l} / 1 \times 10^{6}$ cells, catalog no.: 557696); CD56 (monoclonal, dilution: $0.4 \mu \mathrm{l} / 1 \times 10^{6}$ cells, catalog no.: 556647); and HLA-DR-R-PE (monoclonal, dilution: $0.8 \mu \mathrm{l} / 1 \times 10^{6}$ cells, catalog no.: 560943). Unconjugated markers were added to react with anti-mouse PE-conjugated secondary antibody (eBioscience, San Diego, CA, USA; catalog no.: 11-5921; dilution: 1/200). A total of 10,000 labeled cells were analyzed using a BD LSRFortessa ${ }^{\mathrm{TM}}$ Cell Analyzer (BD Biosciences, San Jose, CA, USA) and the data obtained were analyzed using BD FACSDiva software 6.0 (BD Biosciences).

Cell transplantation. The patients were treated with conventional hematoma removal surgery within $6 \mathrm{~h}$ after hemorrhage. However, in the case of the transplant patients, one end of a $10-\mathrm{cm}$ silicone tube was inserted into the hematoma cavity, the other side was placed subcutaneously, and then sutured. After 2 weeks, and under anesthesia with $5 \mathrm{ml}$ of $2 \%$ lidocaine, the scalp was cut and the extracranial end of the silicone tube was found. BMSCs or Hu-MSCs were grafted through the lumen of the tube. The catheter was then returned as before. A second injection of BMSCs or Hu-MSCs was instilled 1 week later, and this time the indwelling tube was pulled out carefully during the course of $10 \mathrm{~min}$, and finally the scalp was sutured. The patients were sent to the hospital ward for recovery. Antibiotics were given to prevent infection. 
Table I. Inclusion and exclusion criteria.

No. of criterion type

Inclusion

1. Men or women (women of non-child-bearing age only), aged 30-75 years

2. Cerebral hemorrhage observed within $6 \mathrm{~h}$ of the onset of symptoms

3. Radiological:

Maximum diameter of the stroke region in any dimension $\leq 10 \mathrm{~mm}$

Damage not involving more than $50 \%$ of the ipsilateral subventricular zone ${ }^{a}$

4. Moderate to severe persistent neurologic deficit (National Institutes of Health Stroke Scale of 6-21 inclusive)

Exclusion

1. Hematologic disorders or bone marrow suppression

2. Severe medical illness defined as:

Severe heart failure

Severe febrile illness

Hepatic or renal dysfunction

Active cancer

Any evidence of chronic co-morbid condition or unstable acute systemic illness which, in the investigator's opinion, could shorten survival or limit the ability to complete the study

3. Lactating women or pregnant women as determined by positive urine hCG test

4. Considered unwilling or unable to comply with the procedures and study visit schedule outlined in the protocol

5. Unwilling to undergo bone marrow aspiration

${ }^{a}$ The degree of involvement of the ipsilateral subventricular zone was measured on the initial diffusion-weighted image at the two axial level. Severe heart failure, the upper thalamus and head of caudate nucleus. Severe febrile illness, the corona radiata (7-mm upper level).

Treatment protocol. The patients received a standard treatment consisting of: i) Anti-hypertensive medication such as sodium nitrate tome (Hongyuan Group, Quanzhou, Fujian, China); ii) neurotrophic drugs: $\mathrm{N}-\alpha$-acetylglycinamide (Pfizer PharmaceuticalCo.,Ltd.,Shanghai,China), and/or sodium monosialotetrahexosylganglioside injection (Qilu Pharmaceutical Co., Ltd., Jinan, China); iii) intracranial pressure control with 20\% mannitol (Kelun Pharmaceutical Co., Ltd., Chengdu, China); and iv) neurological rehabilitation sessions.

Radiological evaluation. Radiographs were obtained for the patients following admission to the hospital before and 2 days, 4 weeks after operation, and then 3, 6 and 7 days, and 12 months after transplantation. Three independent observers blinded to the assigned treatment assessed the radiographs of each patient for cerebral hemorrhage.

Outcomes. Primary clinical evaluations included assessments of the length of stay in the intensive care unit (ICU), readmission to the ICU, length of stay in the hospital, infection, neurological dysfunction [including National Institutes of Health Stroke Scale (NIHSS), modified Rankin scale (mRS), modified Barthel index (mBI)], time of healing, pain at the iliac crest and infection. For analysis of the outcomes of the primary clinical evaluations, the categorical shift in $\mathrm{mRS}$ at 90 days after treatment was used. Scores from 0 to 5 were used for the mRS, by merging the last scale of 6 (death) with that of 5 (severe disability). Clinical outcomes were followed-up
Table II. Hematoma reabsorption time evaluated by computed tomography scan.

\begin{tabular}{lccc}
\hline Characteristics & $\begin{array}{c}\text { Control } \\
\text { group }\end{array}$ & $\begin{array}{c}\text { Auto-graft } \\
\text { group }\end{array}$ & $\begin{array}{c}\text { Allograft } \\
\text { group }\end{array}$ \\
\hline $\begin{array}{l}\text { Hematoma reabsorbed } \\
\text { partly, months }\end{array}$ & & & \\
$\quad$ Mean & 1.9 & 1.3 & 1.3 \\
$\quad$ Range & $1.3-2.7$ & $0.9-2.1$ & $0.9-2.2$ \\
$\begin{array}{l}\text { Hematoma reabsorbed } \\
\text { completely, months }\end{array}$ & & & \\
Mean & 4.5 & 3.2 & 3.3 \\
Range & $3.5-6.1$ & $2.8-4.3$ & $2.8-4.1$ \\
\hline
\end{tabular}

by phone interview at 4 weeks, and in person at 3, 6, 12, 36 and 60 months.

The secondary evaluations involved checking the percentage of CD4, CD8, CD56 and HLA-DR in peripheral blood 3 years after the transplantation to determine whether the patients had suffered any immune rejections. Secondary and exploratory evaluation outcomes are shown in Table II.

Data collection. Data were collected through person-to-person interactions after training all the interviewers to use standardized scripts. Each interview started with the respondent first 

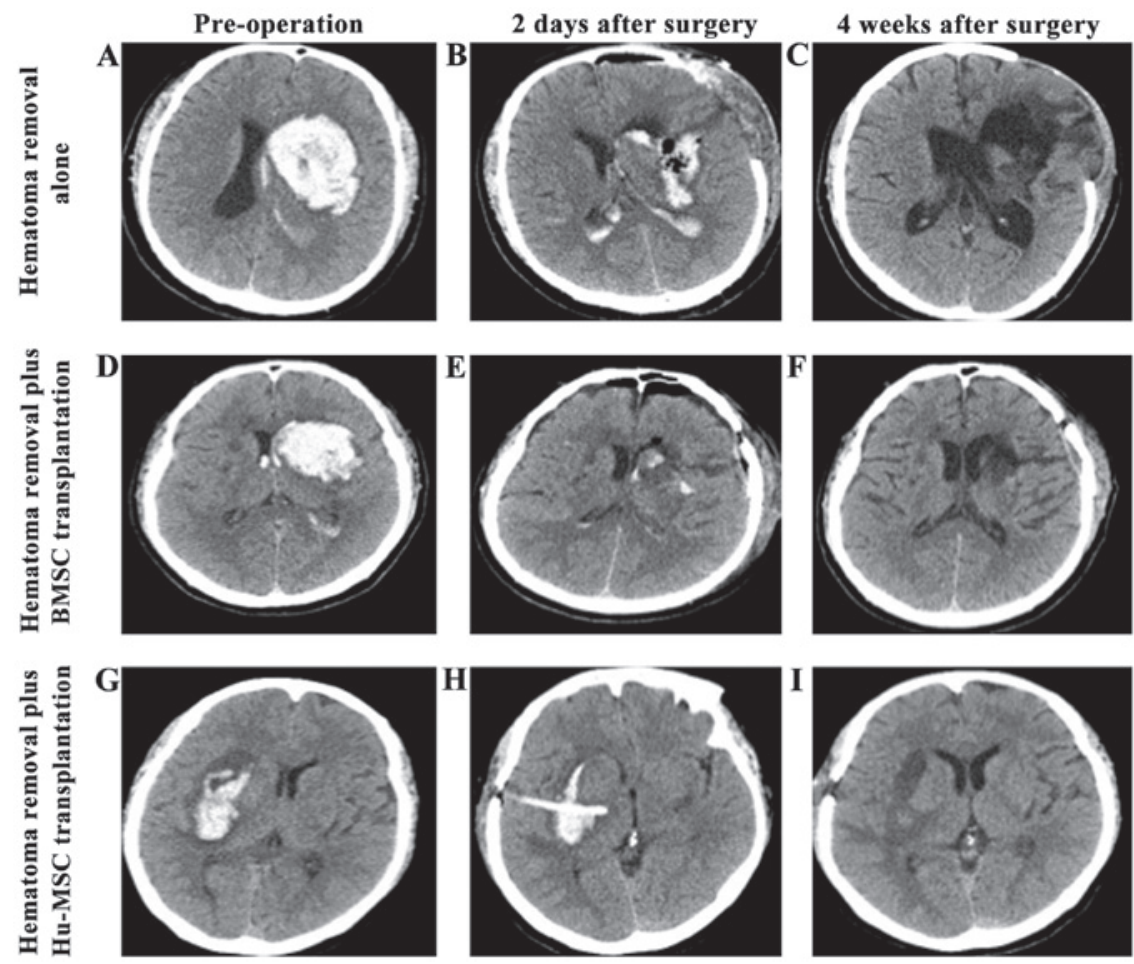

Figure 1. Scan of hematoma site. (A) Left basal ganglia hemorrhage with narrow lateral ventricle compression. (B) A small amount of hematoma remains in the cavity 2 days after surgery. (C) Hematoma cavity has disappeared 2 weeks after transplant; in its place there remains a low-density irregular area. (D) Right basal ganglia hemorrhage with narrow lateral ventricle compression. (E) A small amount of hematoma remains in the cavity 2 days after surgery. (F) Hematoma cavity has disappeared 2 weeks after transplantation; in its place there remain small narrow low-density strips surrounded by dematous brain tissue. (G) Right basal ganglia hemorrhage with narrow lateral ventricle compression. (H) A small amount of hematoma remains in the cavity 2 days after surgery. (I) Hematoma cavity has disappeared 2 weeks after transplantation; in its place there remain small narrow low-density strips surrounded by dematous brain tissue.

reading a short non-technical description of the limbs' function scale explaining the possible limb health states. Investigators blinded to treatment allocations measured the neurological disability of each case using the NIHSS and functional scores for $\mathrm{mRS}$ and $\mathrm{mBI}$.

Statistical analysis. Data obtained were presented as means \pm standard deviation values and compared between groups using one-way ANOVA. $\mathrm{P}<0.05$ was considered to indicate a statistically significant difference.

\section{Results}

General. The patients were older in the Hu-MSC treatment group (Table I). The patients were followed-up for 5 years through the recheck outpatient department and with radiological examinations to confirm the treatment effectiveness.

Hematoma reabsorption analysis. As shown in Fig. 1, the initial hematoma volume was similar in all the cases. Two days after hematoma removal surgery, a small amount of hematoma remained in the cavity. At 2 weeks after $\mathrm{Hu}-\mathrm{MSC}$ (Fig. 1F) or BMSCs (Fig. 1I) transplantation, the bleeding site was evident as low-density small narrow strips surrounded by edematous brain tissue, while the bleeding site in the control group consisted of a larger squared region.

Neurological disability and function evaluation. As shown in Table III, the mean time for hematoma reabsorption was similar in all the groups. The computed tomography (CT) scans for brain tissue healing showed better outcomes in the two cell transplanted groups than in the control group (Fig. 1A-C). Approximately 3.5 months after the graft, CT scans showed the hematoma was completely reabsorbed. NIHSS, mRS and $\mathrm{mBI}$ scores were similar in the cell transplantation groups (Table IV). Nevertheless, the outcomes in the cell-transplanted groups were better than those in the control group at 5 years. Of note, the patients who underwent Hu-MSC allograft had better outcomes than those who underwent autologous BMSC transplantation starting at 3 months and during the rest of the follow-up period, as evaluated by the NIHSS score (Table IV). After 6 months the mRS and mBI score tendencies in each group did not vary significantly.

Donor site complications. In total, 3 patients complained of moderate pain at the iliac crest, and therefore the donor site-related morbidity rate was $42.9 \%$. However, none of the patients suffered permanent pain at the iliac crest, harvesting-related swelling, redness, drainage, infection or neurological deficits.

Intensity of pain and level of treatment-dissatisfaction. During follow-up, patients of all the groups stated to have approximately equal intensity of index operation-related pain. Additionally, 2 patients in the autologous-transplant group (28.5\%) compared to all the patients of the allograft treatment group (100\%) were satisfied or only minimally dissatisfied with the hematoma removal treatment. Thus, patients of the allograft group were 
Table III. Baseline data in patients.

\begin{tabular}{|c|c|c|c|}
\hline Characteristics & $\begin{array}{l}\text { Control } \\
\text { group }\end{array}$ & $\begin{array}{l}\text { Auto-graft } \\
\text { group }\end{array}$ & $\begin{array}{l}\text { Allograft } \\
\text { group }\end{array}$ \\
\hline \multicolumn{4}{|l|}{ Gender, no. } \\
\hline Male & 5 & 5 & 6 \\
\hline Female & 3 & 2 & 3 \\
\hline \multicolumn{4}{|l|}{ Age, years } \\
\hline Mean & 51.32 & 42.43 & 52.36 \\
\hline Range & $40-55$ & $38-44$ & $44-58$ \\
\hline \multicolumn{4}{|l|}{$\mathrm{BMI}, \mathrm{m} / \mathrm{kg}^{2}$} \\
\hline Mean & 25.73 & 24.62 & 25.13 \\
\hline Range & $23.6-26.2$ & $22.7-25.6$ & $22.9-27.3$ \\
\hline \multicolumn{4}{|l|}{$\begin{array}{l}\text { Smoking status, } \\
\text { package-year }\end{array}$} \\
\hline Mean & 8.41 & 9.15 & 12.33 \\
\hline Range & $0-23$ & $0-22$ & $0-23$ \\
\hline \multicolumn{4}{|l|}{$\begin{array}{l}\text { Location of } \\
\text { hemorrhage, no. }\end{array}$} \\
\hline Basal ganglia & 5 & 4 & 5 \\
\hline Subcortical & 3 & 3 & 4 \\
\hline \multicolumn{4}{|l|}{$\begin{array}{l}\text { Hypertension, } \\
\text { years }\end{array}$} \\
\hline Mean & 14.83 & 11.47 & 16.16 \\
\hline Range & $11-23$ & $6-22$ & $9-23$ \\
\hline Hypertension, no. & 8 & 7 & 9 \\
\hline \multicolumn{4}{|l|}{$\begin{array}{l}\text { Diabetes mellitus, } \\
\text { years }\end{array}$} \\
\hline Mean & 3.75 & 3.66 & 5.44 \\
\hline Range & $6-24$ & $9-18$ & $11-21$ \\
\hline $\begin{array}{l}\text { Diabetes } \\
\text { mellitus, no. }\end{array}$ & 2 & 3 & 3 \\
\hline Infection, no. & 4 & 3 & 4 \\
\hline $\begin{array}{l}\text { Total cholesterol, } \\
\mathrm{mg} / \mathrm{dl}\end{array}$ & $5.71 \pm 0.43$ & $5.69 \pm 0.55$ & $5.75 \pm 0.64$ \\
\hline $\begin{array}{l}\text { Triglycerides, } \\
\text { mg/dl }\end{array}$ & $2.32 \pm 0.28$ & $2.46 \pm 0.69$ & $2.49 \pm 0.71$ \\
\hline
\end{tabular}

BMI, body mass index.

significantly less dissatisfied with the treatment compared to those of the autologous group (data not shown).

Serum levels of T-cell subtypes. The serum levels of CD4, CD56 and HLA-DR in the allograft group were negative, while the serum levels of CD8 were $4.6 \%$ positive. There were no evident differences in T-cell subtypes among the 3 groups (data not shown).

\section{Discussion}

In the current study, we reported data of a retrospective comparative study using autologous bone marrow mononuclear cells,
Table IV. Outcome data of total population.

\begin{tabular}{|c|c|c|c|}
\hline Variables & $\begin{array}{l}\text { Control } \\
\text { group }\end{array}$ & $\begin{array}{l}\text { Auto-graft } \\
\text { group }\end{array}$ & $\begin{array}{l}\text { Allograft } \\
\text { group }\end{array}$ \\
\hline $\begin{array}{l}\text { Readmission rate } \\
\text { to } \mathrm{ICU}^{\mathrm{a}}(\%)\end{array}$ & $1 / 8$ & $0 / 7$ & $0 / 9$ \\
\hline ICU LOS (days) & $4.3 \pm 0.8$ & $4.6 \pm 0.3$ & $4.2 \pm 0.9$ \\
\hline Hospital LOS (days) & $29.8 \pm 3.4$ & $28.6 \pm 2.8$ & $29.4 \pm 2.1$ \\
\hline \multicolumn{4}{|l|}{ NIHSS score } \\
\hline $\begin{array}{l}\text { Values during } 24 \mathrm{~h} \\
\text { treatment, \% readings } \\
\text { NIHSS }\end{array}$ & $19.1 \pm 0.3$ & $20.4 \pm 0.7$ & $21.1 \pm 0.6$ \\
\hline $\begin{array}{l}\text { Values before left ICU } \\
\text { treatment, \% readings } \\
\text { NIHSS }\end{array}$ & $16.5 \pm 1.5$ & $15.9 \pm 1.1$ & $16.3 \pm 0.7$ \\
\hline $\begin{array}{l}\text { Values during } 4 \text { weeks } \\
\text { treatment, \% readings } \\
\text { NIHSS }\end{array}$ & $14.9 \pm 0.8$ & $13.3 \pm 0.7$ & $13.6 \pm 0.2$ \\
\hline $\begin{array}{l}\text { Values during } 3 \text { months } \\
\text { treatment, \% readings } \\
\text { NIHSS }\end{array}$ & $14.6 \pm 0.9$ & $12.9 \pm 0.3^{\mathrm{b}}$ & $10.5 \pm 0.6^{\mathrm{b}, \mathrm{c}}$ \\
\hline $\begin{array}{l}\text { Values during } 6 \text { months } \\
\text { treatment, \% readings } \\
\text { NIHSS }\end{array}$ & $13.9 \pm 0.4$ & $10.6 \pm 0.6^{b}$ & $9.6 \pm 0.5^{\mathrm{b}, \mathrm{c}}$ \\
\hline $\begin{array}{l}\text { Values during } 12 \text { months } \\
\text { treatment, \% readings } \\
\text { NIHSS }\end{array}$ & $13.6 \pm 0.6$ & $9.3 \pm 0.4^{\mathrm{b}}$ & $8.9 \pm 0.8^{\mathrm{b}, \mathrm{c}}$ \\
\hline $\begin{array}{l}\text { Values during } 24 \text { months } \\
\text { treatment, \% readings } \\
\text { NIHSS }\end{array}$ & $13.1 \pm 0.3$ & $9.6 \pm 0.3^{b}$ & $8.1 \pm 0.3^{\mathrm{b}, \mathrm{c}}$ \\
\hline $\begin{array}{l}\text { Values during } 36 \text { months } \\
\text { treatment, \% readings } \\
\text { NIHSS }\end{array}$ & $13.3 \pm 0.6$ & $9.1 \pm 0.5^{b}$ & $7.8 \pm 0.6^{b, c}$ \\
\hline $\begin{array}{l}\text { Values during } 60 \text { months } \\
\text { treatment, \% readings } \\
\text { mRS score }\end{array}$ & $13.3 \pm 0.4$ & $9.3 \pm 0.3^{b}$ & $7.6 \pm 0.5^{\mathrm{b}, \mathrm{c}}$ \\
\hline
\end{tabular}

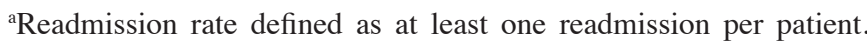
${ }^{\mathrm{b}} \mathrm{P}<0.05$, compared with control. ${ }^{\mathrm{c}} \mathrm{P}<0.05$, compared to auto-graft group. ICU, intensive care unit; LOS, length of stay (days); NIHSS, National Institutes of Health Stroke Scale.

Hu-MSCs or surgery alone to treat cerebral hemorrhage. All the patients agreed to the offered treatment options. Success of the treatment was observed in $100 \%$ of the $\mathrm{Hu}-\mathrm{MSC}$ grafted and the autologous bone marrow mononuclear cells grafted groups. This is the first time, to the best of our knowledge, that the safety of an Hu-MSCs allograft in vivo in humans has been assessed over a period of 5 years.

Different tissue-derived adult stem cells can be employed as donor cells for transplantation to treat neurogenetic disorders. An important factor in considering stem cell grafting for therapy is the possibility of an immunogenic complication such as a host graft rejection. Taking this into consideration, levels of CD8, CD56 and HLA-DR, which are known immunological rejection markers, were measured in 
all the graft patients. There were no elevations in the levels of CD8, CD56 or HLA-DR in either group, while the level of $\mathrm{CD} 4{ }^{+} \mathrm{T}$-cells was similar in the two groups after 5 years of the grafting procedure. Some investigators have reported elevated endogenous neurogenesis via a CD4 ${ }^{+} \mathrm{T}$-cell-dependent mechanism (14). Given these results and the fact that no adjunctive immunosuppressants were administered, the data suggest no immunological rejection or disorder in the Hu-MSCs graft group. A limitation of the present study is that the level of HLA-G, which is reported as a contributing factor to inducing stronger immunosuppression (15) and a prognostic indicator of graft tolerance $(16,17)$ was not observed in the allograft group when compared to the autograft group.

MSCs can be harvested from a variety of mesenchymal tissues, and have different characteristics in an immune response depending on their origin. Placenta-derived MSCs show less inhibition to $\mathrm{CD}^{+}{ }^{+} \mathrm{T}$-cell stimulation than bone marrow-derived stem cells (18). The current research for favorable outcomes suggests an optimal intra-brain administration of cells 2 weeks post-hemorrhage, and a therapeutic dose of 1 million cells. This period of opportunity poses a challenge in generating enough stem cells from freshly harvested autologous tissue sources.

An aim of the present study was to evaluate the effectiveness and tolerance of Hu-MSCs compared to the autologous bone-marrow-mononuclear-cell-grafting in the treatment of cerebral hemorrhage. Taking all results into account, the present findings show that the $\mathrm{Hu}-\mathrm{MSC}$ group performed better overall than the control or even the autologous graft group, demonstrating the effectiveness of the Hu-MSC graft treatment for cerebral hemorrhage. Of note, 3 patients in the autologous group suffered moderate donor site complications at the iliac crest region. By contrast, patients treated with $\mathrm{Hu}-\mathrm{MSCs}$ claimed minimal dissatisfaction concerning the surgery during follow-up.

In summary, the present study has shown that patients treated with $\mathrm{Hu}-\mathrm{MSC}$ had good functional recovery, no complications, reduced treatment dissatisfaction, and a lack of donor site complications at the iliac crest region. Therefore we recommend that the use of $\mathrm{Hu}$-MSCs offered to suitable patients as a valuable alternative for autologous grafting. Harvesting Hu-MSCs is easy, and is perceived as ethically correct. In conclusion, our findings suggest that Hu-MSCs grafting is an effective and safe method for the treatment of cerebral hemorrhage and should be seriously considered in future studies.

\section{Acknowledgements}

The present study was supported by the National High Technology Research and Development Program of (863 Program), nos. 2011AA020101 and 2012A020905.
2. D'souza N, Rossignoli F, Golinelli G, Grisendi G, Spano C, Candini O, Osturu S, Catani F, Paolucci P, Horwitz EM, et al: Mesenchymal stem/stromal cells as a delivery platform in cell and gene therapies. BMC Med 13: 186, 2015.

3. Dominici M, Le Blanc K, Mueller I, Slaper-Cortenbach I, Marini F, Krause D, Deans R, Keating A, Prockop DJ and Horwitz E: Minimal criteria for defining multipotent mesenchymal stromal cells. The International Society for Cellular Therapy position statement. Cytotherapy 8: 315-317, 2006.

4. Shinozuka K, Dailey T, Tajiri N, Ishikawa H, Kaneko Y and Borlongan CV: Stem cell transplantation for neuroprotection in stroke. Brain Sci 3: 239-261, 2013.

5. Borlongan CV, Glover LE, Tajiri N, Kaneko Y and Freeman TB: The great migration of bone marrow-derived stem cells toward the ischemic brain: Therapeutic implications for stroke and other neurological disorders. Prog Neurobiol 95: 213-228, 2011.

6. Liu X, Ye R, Yan T, Yu SP, Wei L, Xu G, Fan X, Jiang Y, Stetler RA, Liu G, et al: Cell based therapies for ischemic stroke: From basic science to bedside. Prog Neurobiol 115: 92-115, 2014.

7. Dailey T, Metcalf C, Mosley YI, Sullivan R, Shinozuka K, Tajiri N, Pabon M, Acosta S, Kaneko Y, van Loveren H, et al: An update on translating stem cell therapy for stroke from bench to bedside. J Clin Med 2: 220-241, 2013.

8. Zou Z, Zhang Y, Hao L, Wang F, Liu D, Su Y and Sun H: More insight into mesenchymal stem cells and their effects inside the body. Expert Opin Biol Ther 10: 215-230, 2010.

9. Qu Z, Guo L, Fang G, Cui Z, Guo S and Liu Y: Biological characteristics and effect of human umbilical cord mesenchymal stem cells (hUC-MSCs) grafting with blood plasma on bone regeneration in rats. Cell Biochem Biophys 63: 171-181, 2012.

10. Qu Z, Guo S, Fang G, Cui Z and Liu Y: AKT pathway affect bone regeneration in nonunion treated with umbilical cord-derived mesenchymal stem. Cell Biochem Biophys 71: 1543-1551, 2015.

11. Qu Z, Fang G, Cui Z and Liu Y: Cell therapy for bone nonunion: A retrospective study. Minerva Med 106: 315-321, 2015.

12. Kim SJ, Moon GJ, Chang WH, Kim YH and Bang OY; STARTING-2 (STem cell Application Researches and Trials In NeuroloGy-2) collaborators: Intravenous transplantation of mesenchymal stem cells preconditioned with early phase stroke serum: Current evidence and study protocol for a randomized trial. Trials 14: 317, 2013.

13. Qu ZG, Liu Y, Guo LB and Bi WW: Percutaneous radiological autologous bone-marrow mesenchymal stem cells grafting integrating blood plasma by injection in the part of thigh fracture: Seven-month follow-up effect evaluation in one case. J Clin Reh Tis Eng Res 13: 7393-7396, 2009.

14. Saino O, Taguchi A, Nakagomi T, Nakano-Doi A, Kashiwamura S, Doe N, Nakagomi N, Soma T, Yoshikawa H, Stern DM, et al: Immunodeficiency reduces neural stem/progenitor cell apoptosis and enhances neurogenesis in the cerebral cortex after stroke. J Neurosci Res 88: 2385-2397, 2010.

15. Hunt JS, Petroff MG, McIntire RH and Ober C: HLA-G and immune tolerance in pregnancy. FASEB J 19: 681-693, 2005.

16. Menier C, Rouas-Freiss N, Favier B, LeMaoult J, Moreau P and Carosella ED: Recent advances on the non-classical major histocompatibility complex class I HLA-G molecule. Tissue Antigens 75: 201-206, 2010.

17. Lee JM, Jung J, Lee HJ, Jeong SJ, Cho KJ, Hwang SG and Kim GJ: Comparison of immunomodulatory effects of placenta mesenchymal stem cells with bone marrow and adipose mesenchymal stem cells. Int Immunopharmacol 13: 219-224, 2012.

18. Fazekasova H, Lechler R, Langford K and Lombardi G: Placenta-derived MSCs are partially immunogenic and less immunomodulatory than bone marrow-derived MSCs. J Tissue Eng Regen Med 5: 684-694, 2011.

\section{References}

1. Qureshi AI, Mendelow AD and Hanley DF: Intracerebral haemorrhage. Lancet 373: 1632-1644, 2009. 